\title{
Senam Aerobik Intensitas Sedang Tingkatkan Memori Jangka Pendek Siswa SMK yang Diukur Menggunakan Nonsense Syllable Test
}

\author{
Aerobic Gymnastics Intensity Increases Short-Term Memory of Vocational Students Measured \\ Using a Nonsense Syllable Test
}

\author{
Dinda Tiara Firdaus ${ }^{1}$, Yanuarita Tursinawati², Ika Dyah Kurniati \\ ${ }^{1}$ Mahasiswi Fakultas Kedokteran Universitas Muhammadiyah Semarang \\ ${ }^{2}$ Staf Pengajar Fakultas Kedokteran Universitas Muhammadiyah Semarang \\ *Penulis Korespondensi. Email: dindatiarafirdaus@gmail.com \\ Telepon: +622476913760/ 082135420516
}

\begin{abstract}
Abstrak
Latar Belakang: Gangguan fungsi memori jangka pendek dapat timbul salah satunya akibat aktivitas fisik yang rendah. Beberapa penelitian menyatakan bahwa aktivitas fisik seperti olahraga aerobik yang dilakukan pada kelompok dewasa muda diketahui mampu meningkatkan fungsi memori jangka pendek. Memori jangka pendek memiliki peran penting dalam kehidupan sehari-hari, terutama dalam proses pengolahan informasi. Tujuan penelitian ini adalah menganalisis perbedaan fungsi memori jangka pendek yang diukur menggunakan nonsense syllable test sebelum dan setelah perlakuan senam aerobik intensitas sedang.

Metode: Penelitian kuasi eksperimental dengan desain pre and post-test. Subjek penelitian adalah siswi SMK Widya Praja Ungaran $(n=36)$ berusia 16-17 tahun yang dipilih secara purposive sampling. Sampel terbagi menjadi dua yaitu kelompok kontrol dan perlakuan. Penelitian ini menggunakan instrumen nonsense syllable test untuk pengukuran memori jangka pendek. Analisis menggunakan uji t berpasangan dan t tidak berpasangan.

Hasil: Skor pre-test dan post-test pada kelompok kontrol dan perlakuan mengalami kenaikan. Namun, kenaikan skor pada kelompok perlakuan lebih tinggi yaitu 5 sedangkan pada kelompok kontrol 1,17. Terdapat perbedaan bermakna skor memori jangka pendek setelah perlakuan antar kelompok kontrol dan perlakuan $(\mathrm{p}=0,023)$. Terdapat perbedaan yang bermakna memori jangka pendek sebelum dan setelah perlakuan pada kelompok perlakuan $(\mathrm{p}=0,000)$

Kesimpulan: Senam aerobik intensitas sedang sesi tunggal dapat meningkatkan fungsi memori jangka pendek
\end{abstract}

Kata Kunci: Memori jangka pendek, nonsense syllable test, senam aerobik intensitas sedang.

\begin{abstract}
Background: Impaired short-term memory can happen because of low physical activity. Some studies suggest that aerobic exercise done by the young adult can improve the short-term memory function. Short-term memory has an important role in daily life, especially in the information management process. The aim of this research is to analyze the difference of short-term memory function measured using nonsense syllable test before and after being treated with medium intensity aerobic gymnastic.

Method: This research was a quasi-experimental research using pre and post-test design. Research samples were taken purposively from the female students of Vocational Senior School of Widya Praja Ungaran ( $n=36$ age $=16-17$ years old) who were divided into two groups, those are control and treatment group. The instrument used to measure the shortterm memory function before and after the treatment was nonsense syllable test.The short-term memory was analyzed using paired test and unpaired $t$.

Result: Pre and post test score of both control and treatment groups were increased. However, the increase of the treatment group score was higher than the control group, in which the increasing in the treatment group is 5 score, while the increasing in the control group is 1,17. There was a statistical significant difference of the short term memory between the control and treatment groups $(p=0,023)$. In addition, there was also significant difference of the shortterm memory before and after the treatment in the treatment group $(p=0.000)$.

Conclusion: Aerobic gymnastic in medium intensity of one session can improve short-term memory function.
\end{abstract}

Keywords: Short-term memory, nonsense syllable test, medium intensity aerobic exercise. 


\section{PENDAHULUAN}

Memori adalah kemampuan untuk menyimpan, mempertahankan, dan mengingat informasi dari pengalaman masa lalu pada otak manusia. Memori jangka pendek memegang peranan penting, karena informasi yang baru saja didapat pada mulanya diendapkan di memori jangka pendek. Selanjutnya informasi ini segera dilupakan atau dipindahkan ke dalam mode ingatan jangka panjang yang lebih permanen. ${ }^{2}$

Salah satu masalah kesehatan di bidang kognitif adalah kemunduran fungsi memori jangka pendek. Kemunduran fungsi memori jangka pendek dapat berupa mudah lupa. Hal ini dialami oleh $39 \%$ orang berusia 50-59 tahun, meningkat menjadi $85 \%$ pada usia lebih dari 80 tahun dan menjadi salah satu masalah utama pada lanjut usia. Kemunduran fungsi memori jangka pendek menyebabkan seorang individu tidak dapat memindahkan informasi yang baru saja didapatkan menuju ke mode memori jangka panjang. Terganggunya proses tersebut menyebabkan seorang individu sulit untuk menyimpan dan memanggil kembali informasi yang baru saja didapatkannya. Dampaknya adalah seseorang akan sulit untuk mempelajari suatu hal yang baru. ${ }^{3,4,5}$

Memori dipengaruhi oleh faktor yang sangat kompleks salah satunya adalah aktivitas fisik seperti olahraga. Fungsi kognitif yang baik telah terbukti berkorelasi dengan aktivitas fisik yang teratur. Gangguan fungsi kognitif yang berupa memori jangka pendek, motivasi belajar, dan konsentrasi timbul akibat aktivitas fisik yang rendah. ${ }^{1,6}$ American Academy of Neurology (AAN) merekomendasikan bahwa untuk mengurangi resiko penurunan fungsi memori hendaknya setiap orang berolahraga. ${ }^{4,5}$ Olahraga aerobik sesi tunggal akan meningkatkan aktivitas serotonin dan Insulin Growth Factor 1 (IGF1) pada otak. Kedua hormon ini berperan penting dalam neurogenesis hippocampus serta kinerja memori jangka pendek. ${ }^{5,10}$ Salah satu jenis olahraga aerobik yang populer bagi masyarakat adalah senam aerobik. Intensitas olahraga dapat diukur menggunakan Denyut Nadi Maksimal (DNM). Angka DNM diperoleh dari rumus 220-usia. Senam aerobik berintensitas sedang ketika denyut nadi mencapai $64-76 \%$ DNM. ${ }^{7,8}$ Olahraga aerobik dengan intensitas ringan dan sedang meningkatkan CBF sehingga dapat menyebabkan peningkatan kinerja memori jangka pendek. ${ }^{9,10}$

Penelitian ini bertujuan untuk menganalisis perbedaan fungsi memori jangka pendek sebelum dan setelah perlakuan senam aerobik intensitas sedang pada kelompok kontrol dan perlakuan. Kapasitas memori jangka pendek dapat diukur menggunakan beberapa instrumen, salah satunya nonsense syllable test. Nonsense syllable test memiliki keunggulan metode lebih sederhana, pengukuran dapat dilakukan secara massal sehingga waktu yang diperlukan lebih efektif dan efisien. ${ }^{11}$

\section{METODE}

Jenis penelitian yang digunakan adalah eksperimen menggunakan rancangan kuasi eksperimental dengan desain pre and posttest. Penelitian dilakukan di SMK Widya Praja Ungaran Barat. Sampel penelitian adalah siswi kelas 11 Jurusan Administrasi Perkantoran yang memenuhi kriteria Inklusi: Jenis kelamin wanita, berusia 16 - 17 tahun, memiliki tingkat aktifitas fisik "sangat kurang" atau "kurang baik" (skor PAQ-A $\leq$ 2), dan bersedia diikutsertakan dalam penelitian. Kriteria Ekslusi penelitian ini adalah memiliki riwayat trauma kepala yang menimbulkan gejala neurologis, memiliki riwayat tumor otak, memiliki riwayat menderita epilepsi, memiliki riwayat menderita infeksi susunan saraf pusat, mengidap penyakit infeksi dan/atau penyakit sistemik, kebiasaan konsumsi suplemen neurotropik dan suplemen otak, mengalami stress, ansietas, dan/atau depresi (Skor DASS $>18$ ), dan memiliki kadar Hemoglobin <12 g/dl. Sampel yang mengundurkan diri di tengah berjalannya waktu penelitian termasuk dalam kriteria drop out. Penelitian ini akan 
mengambil sampel dengan cara purpossive sampling berdasarkan kriteria yang telah ditentukan oleh peneliti. Jumlah subjek penelitian adalah 36 orang. Subjek penelitian dibagi menjadi dua kelompok yaitu kelompok kontrol dan kelompok perlakuan.

Pemilihan subjek penelitian dilakukan dengan memberikan kuisioner Calon subjek penelitian mengisi kuisioner screening subjek penelitian, kuisioner DASS, dan kuisioner PAQ-A. Setelah mengisi tiga kuisioner tersebut, calon subjek penelitian yang sekiranya memenuhi kriteria inklusi dan tidak terdapat kriteria eksklusi penelitian akan dilakukan pemeriksaan hemoglobin menggunakan alat ukur hemoglobin digital merk easytouch. Kadar hemoglobin normal pada wanita adalah 12-16 g/dl. Kadar hemoglobin siswi yang $<12 \mathrm{~g} / \mathrm{dl}$ termasuk dalam kriteria ekslusi. Calon subjek penelitian yang memenuhi kriteria inklusi dan tidak terdapat kriteria eksklusi penelitian diminta persetujuannya untuk menjadi subjek penelitian.

Pada penelitian ini, variabel bebas berupa olahraga aerobik intensitas sedang serta variabel terikat berupa memori jangka pendek. Normalitas distribusi data dianalisis dengan uji Saphiro-Wilk. Hasil tes memori jangka pendek sebelum dan setelah perlakuan setiap kelompok diuji menggunakan uji $\mathrm{t}$ berpasangan karena distribusi data normal. Hasil tes memori jangka pendek antarkelompok diuji menggunakan uji t tidak berpasangan karena distribusi data normal. Perbedaan dianggap bermakna apabila nilai $\mathrm{p}<0,05$.

Studi pendahuluan dilakukan sebelum penelitian berlangsung. Studi pendahuluan ini bertujuan untuk menentukan gerakan senam aerobik yang dapat mencapai intensitas sedang. Intensitas sedang tercapai ketika denyut jantung mencapai $64-76 \%$ Denyut Nadi Maksimal (DNM).

\section{HASIL}

Subjek penelitian ini adalah 36 siswi kelas XI SMK Widya Praja Ungaran Subjek penelitian dibagi menjadi dua kelompok yaitu kelompok kontrol yang tidak diberi intervensi apapun dan kelompok perlakuan yang diintervensi senam aerobik intensitas sedang sesi tunggal. Penentuan subjek penelitian menggunakan metode matching sample berdasarkan usia dan Indeks Massa Tubuh (IMT).

Hasil pre-test dan post-test memori jangka pendek masing-masing sampel pada kelompok kontrol didapatkan rata-rata pretest 10,33 dan rata-rata post-test 11,50. Kenaikan skor pre-test dan post-test pada kelompok kontrol sebesar 1,17. Hasil pre-test dan post-test memori jangka pendek masingmasing sampel pada kelompok perlakuan didapatkan rata-rata pre-test 9,16 dan rata-rata post-test 14,16 . Kenaikan skor pre-test dan post-test pada kelompok perlakuan sebesar 5 .

Fungsi memori jangka pendek sebelum perlakuan pada kelompok kontrol dan perlakuan. Diketahui nilai $\mathrm{p}=0,218$ sehingga menunjukkan perbedaan yang bermakna. Sebagaimana ditunjukkan pada tabel 2. Fungsi memori jangka pendek setelah perlakuan pada kelompok kontrol dan perlakuan diketahui nilai $\mathrm{p}\urcorner=0,023$. Sehingga menunjukkan perbedaan yang bermakna. Sebagaimana ditunjukkan pada tabel 3.

Memori jangka pendek pada masingmasing kelompok dibandingkan untuk mengetahui perbedaan memori jangka pendek masing-masing kelompok. Kelompok kontrol memperoleh $\mathrm{p}$ value 0,076 sedangkan kelompok perlakuan memperoleh $\mathrm{p}$ value 0,000 . Artinya, peningkatan skor memori pada kelompok kontrol hasilnya tidak bermakna secara statistik, sedangkan pada kelompok perlakuan bermakna secara statistik sebagaimana ditunjukkan pada tabel 4. 
Tabel 1. Karakteristik Responden

\begin{tabular}{lcc}
\hline Karakteristik & $\mathbf{N}(\%)$ & Rerata \pm SD \\
\hline Kelompok & & \\
Kontrol & $18(100)$ & \\
Perlakuan & $18(100)$ & \\
\hline Usia & & $16,33 \pm 0,478$ \\
16 & $24(66,7)$ & \\
17 & $12(33,3)$ & \\
\hline IMT & & $19,44 \pm 2,78$ \\
$<18,5$ & $14(38,9)$ & \\
(Kurang) & $20(55,6)$ & \\
$18,2-22,9$ & $2(5,6)$ & \\
(Normal) & & \\
$\geq 23$ (Lebih) & & \\
\hline Skor PAQ-A & & \\
1 (Sangat & $28(77,8)$ & \\
kurang) & $8(22,2)$ & \\
2 (Kurang) & \\
\hline N Jumlah; SD= Simpang baku &
\end{tabular}

\section{PEMBAHASAN}

Skor pre-test dan post-test pada kelompok kontrol dan perlakuan mengalami kenaikan. Namun, kenaikan skor pada kelompok perlakuan lebih tinggi yaitu 5 sedangkan pada kelompok kontrol 1,17. Hal ini membuktikan bahwa senam aerobik intensitas sedang sesi tunggal dapat memberikan respon akut berupa peningkatan fungsi memori jangka pendek pada kelompok perlakuan.31,17,8 Olahraga aerobik intensitas sedang terbukti meningkatkan aliran darah, oksigen dan nutrisi yang disalurkan ke otak.7,8,5

Fungsi memori jangka pendek sebelum perlakuan pada kelompok kontrol dan perlakuan tidak terdapat perbedaan yang bermakna. Tidak adanya intervensi pada kedua kelompok sebelum perlakuan menyebabkan fisiologi memori tetap dalam kondisi stabil. Merujuk pada karakteristik memori jangka pendek yang akan mengalami dua kemungkinan, yaitu: segera dilupakan atau dipindahkan ke dalam mode ingatan jangka panjang yang lebih permanen. Syarat supaya memori jangka pendek dapat dipindahkan ke dalam mode ingatan jangka panjang maka perlu latihan aktif atau pengulangan. ${ }^{3,19}$
Fungsi memori jangka pendek setelah perlakuan pada kelompok kontrol dan perlakuan terdapat perbedaan yang bermakna. Hal ini sesuai dengan penelitian sebelumnya yang menyatakan bahwa memori jangka pendek meningkat pada remaja dan dewasa muda setelah melakukan olahraga aerobik lari sesi tunggal selama 30 menit. ${ }^{7,8}$ Hal ini terjadi karena olahraga aerobik intensitas sedang dapat meningkatan konsumsi oksigen.

Peningkatan konsumsi oksigen akan melebarkan pembuluh darah otot, sehingga meningkatkan aliran balik vena, curah jantung, serta Cerebrovascular Blood Flow (CBF). ${ }^{19,40,16}$ Peningkatan ini akan memperbaiki fungsi dan metabolisme sel otak serta saraf. Efek dari perbaikan fungsi dan metabolisme sel otak akan menyebabkan proses mengingat menjadi lebih baik. ${ }^{4,27,30}$

Peningkatan skor memori jangka pendek sebelum dan setelah tidak diberi perlakuan apapun pada kelompok kontrol hasilnya tidak bermakna. Sedangkan pada kelompok perlakuan bermakna secara statistik. Hal ini sesuai dengan hipotesis awal dimana peningkatan fungsi memori jangka pendek kelompok perlakuan lebih baik dibandingkan dengan kelompok kontrol. 
Tabel 2. Hasil nonsense syllable test sebelum perlakuan pada kelompok kontrol dan perlakuan

\begin{tabular}{lcc}
\hline \multicolumn{1}{c}{ Pemeriksaan } & $\begin{array}{c}\text { Rerata } \pm \mathbf{S B} \\
\text { median } \\
(\text { min-maks })\end{array}$ & Nilai $\boldsymbol{p}^{\#}$ \\
\hline Pre-test & $10,33 \pm 2,99 ;$ & \\
Kelompok kontrol & $10(4-16)$ & $0,218^{*}$ \\
Pre-test & & \\
Kelompok perlakuan & $9,16 \pm 2,57 ; 9$ & \\
& $(5-15)$ & \\
\hline
\end{tabular}

Tabel 3. Hasil nonsense syllable test setelah perlakuan pada kelompok kontrol dan perlakuan

\begin{tabular}{ccc}
\hline Pemeriksaan & $\begin{array}{c}\text { Rerata } \pm \text { SB; } \\
\text { median }(\text { min- } \\
\text { maks) }\end{array}$ & Nilai $\boldsymbol{p}^{\#}$ \\
\hline $\begin{array}{c}\text { Post-test } \\
\text { Kelompok } \\
\text { kontrol }\end{array}$ & $\begin{array}{c}(1,50 \pm 3,61 ; 12 \\
\\
\text { Post-test }\end{array}$ & $0,023^{*}$ \\
$\begin{array}{c}\text { Kelompok } \\
\text { perlakuan }\end{array}$ & $(7-18)$ & \\
\hline
\end{tabular}

Tabel 4. Hasil nonsense syllable test sebelum dan setelah perlakuan pada antar kelompok

\begin{tabular}{llc}
\hline Pemeriksaan & \multicolumn{1}{c}{$\begin{array}{c}\text { Rerata } \pm \text { SB; median } \\
\text { (min-maks) }\end{array}$} & Nilai $p^{\#}$ \\
\hline $\begin{array}{l}\text { Kelompok } \\
\text { kontrol }\end{array}$ & $10,33 \pm 2,99 ; 10(4-$ & $0,076^{*}$ \\
$\begin{array}{l}\text { Pre-test } \\
\text { Post-test }\end{array}$ & $16)$ & \\
& $11,50 \pm 3,61 ; 12(5-$ & \\
Kelompok & $18)$ & $0,000^{* *}$ \\
perlakuan & & \\
Pre-test & $9,16 \pm 2,57 ; 9(5-15)$ \\
Post-test & $14,16 \pm 3,07 ; 15(7-$ \\
& $18)$ & \\
\hline$p^{\#}$ Uji t berpasangan; ${ }^{*}>0,05$ tidak bermakna; ${ }^{* *}<0,05$ bermakna
\end{tabular}

Berdasarkan hasil penelitian ini terbukti bahwa senam aerobik intensitas sedang sesi tunggal dapat memberi respon akut atau segera terhadap peningkatan fungsi memori jangka pendek pada orang-orang yang memiliki tingkat aktivitas fisik sangat kurang dan kurang. Tidak adanya intervensi senam aerobik intensitas sedang sesi tunggal pada kelompok kontrol menyebabkan masukan oksigen, produksi hormon dan neurotransmiter endorfin, dopamin, dan serotonin tidak meningkat. Hal ini akan menyebabkan proses mengingat menjadi tidak optimal. ${ }^{1,2,4,41}$

Penelitian ini memiliki beberapa keterbatasan yaitu adanya faktor perancu seperti aktivitas tidak terpantau yang dapat mempengaruhi memori. Misalnya aktivitas pembelajaran, bermain game. Pengambilan data memori menggunakan metode nonsense syllable test lebih ditujukan untuk menilai 
memori jangka pendek visual, sehingga terdapat keterbatasan untuk menilai jenis memori lain. Selain itu, pengujian dan perhitungan memori jangka pendek masih secara subjektif oleh peneliti. Keterbatasan alat untuk memantau denyut nadi menyebabkan denyut nadi subjek penelitian hanya diukur setelah senam aerobik intensitas sedang pada saat studi pendahuluan. Akibatnya denyut nadi tidak dapat dipantau agar tetap dalam batas $64-76 \%$ DNM.

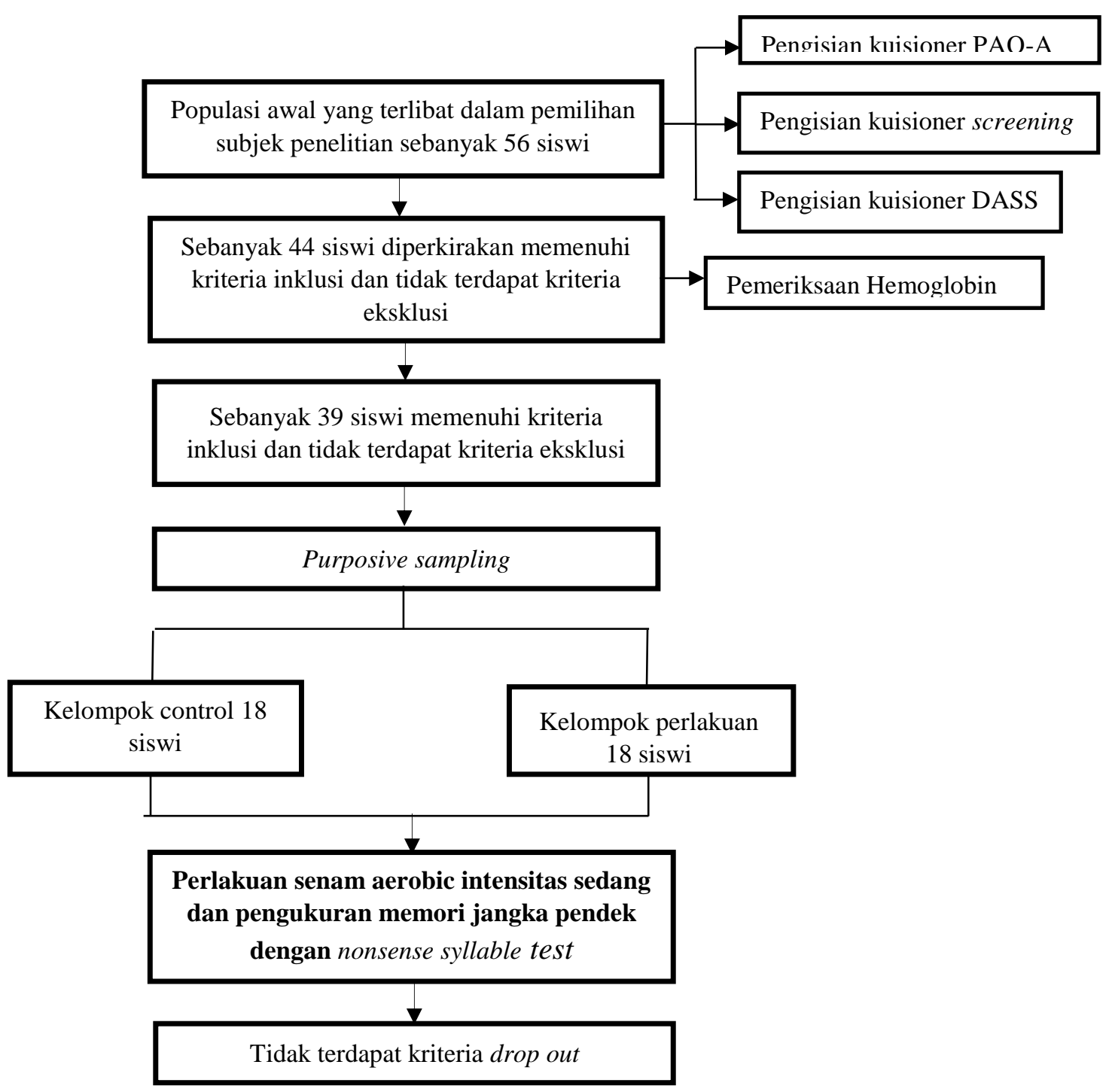

Gambar 1. Bagan proses recruitment sampel 


\section{KESIMPULAN DAN SARAN}

\section{Kesimpulan}

Berdasarkan penelitian dapat disimpulkan bahwa senam aerobik intensitas sedang sesi tunggal dapat meningkatkan fungsi memori jangka pendek.

\section{Saran}

Perlu dilakukan penelitian lebih lanjut pada populasi yang lebih luas, jumlah sampel lebih besar, dan bandingkan memori jangka pendek antar jenis kelamin pada kelompok kontrol maupun perlakuan. Perhatikan faktor lain yang dapat mempengaruhi fungsi memori jangka pendek seperti intelegensi dan kebiasaan dalam menghafal pada setiap subjek. Pengukuran fungsi memori jangka pendek pada penelitian ini masih bersifat subjektif, maka perlu digunakan alat ukur fungsi memori jangka pendek yang bersifat objektif seperti electroenchepalography. Diperlukan alat yang dapat mengukur denyut jantung selama senam aerobik agar denyut jantung tetap dalam batas 64-76\% DNM.

\section{DAFTAR PUSTAKA}

1. Junaidi MB. Hubungan antara aktivitas fisik terhadap memori kerja murid SMA Don Bosco III Bekasi. Jurnal Sari Pediatri. 2016; 18: 25159.

2. Mcdonald M. Effects of acute aerobic exercise on short term memory. Sci Med. 2016: 11-6.

3. Wreksoatmodjo BR. Pengaruh aktivitas fisik terhadap fungsi kognitif lanjut usia di Jakarta. Jurnal CDK. 2016; 43: 7-12.

4. Wahyuni A. Pengaruh aktivitas dan latihan fisik terhadap fungsi kognitif pada penderita demensia. Jurnal Berkala Kedokteran. 2016; 12-6.

5. Effendi AD. Hubungan antara aktivitas fisik dan kejadian demensia pada lansia di upt pelayanan sosial lanjut usia Jember. Jurnal Pustaka Kesehatan. 2014; 2: 332-36.
6. Ogoh S,Tsukamoto H, Hirasawa A, Hasegawa H, Hirose N, Hashimoto T. The effect of changes in cerebral blood flow on cognitive function during exercise. Adv Student Sci. 2014; 2: 1-8.

7. Susanto Y. Pengaruh olahraga ringan terhadap memori jangka pendek pada wanita dewasa. Jurnal JKM. 2009; 144-51.

8. Anggraheni RH. Pengaruh lari sebagai olahraga aerobik intensitas sedang terhadap memori jangka pendek mahasiswa pendidikan dokter Universitas Diponegoro. Jurnal Media Medika. 2017; 6: 1106-15.

9. Hanjani A. Pengaruh olahraga aerobik rutin terhadap memori jangka pendek mahasiswa FK Undip. Jurnal Media Medika. 2015; 4: 379-88.

10. Paulsen F. Sobotta Atlas Anatomi Manusia Edisi 23. Jakarta: EGC; 2012.

11. McDonald M.Efffect of acute aerobic excercise on short term memory. $S c i$ Med. 2016; 11-6.

12. Sherwood L. Fisiologi Manusia Edisi 5. Jakarta: Penerbit buku kedokteran EGC; 2014; 120-24.

13. Guyton CA. Fisiologi Manusia Jakarta: Penerbit buku kedokteran EGC; 2009; 133-37.

14. Prasetya A. Pengaruh minuman isotonik terhadap memori pada keadaan dehidrasi (studi perbandingan dengan air mineral). Jurnal Media Medika. 2015; 4: 407-17.

15. Ayatasya H.Pengaruh makronutrien terhadap performa kognitif remaja. Jurnal Media Medika. 2017; 6: 61121.

16. Marpaung DR.Pengaruh pemberian senam otak terhadap memori jangka pendek pada mahasiswa ikor Fik Unimed. [Skripsi]. Medan: Universitas Negeri Medan. 2017; 1: 21-9.

17. Zulkarnain.Peran latihan fisik teratur terhadap fungsi memori dan kognitif wanita pascamenopause. Jurnal 
Fakultas Kedokteran Syah Kuala. 2014; 4(3): 167-74.

18. Christian R.Pengaruh minuman yang mengandung vitamin $\mathrm{c}$ terhadap peningkatan memori jangka pendek pada remaja perempuan. Jurnal Kedokteran Universitas Kristen Maranatha. 2014; 1-8.

19. Hidayaty D.Hubungan aktivitas fisik dan aktivitas kognitif terhadap kejadian demensia pada lansia di Kelurahan Sukabumi Selatan tahun 2012. [Skripsi]. Jakarta: Universitas Islam Negeri Syarif Hidayatullah.2012; 24-6.

20. Didehbani N, Lu H,Monti JM. Shorter term aerobic exercise improves brain, cognition, and cardiovascular fitness in aging participants. Sci Med. 2013; 5: 1-9.

21. Qolby QN.Pengaruh latihan skipping rutin terhadap memori jangka pendek pada dewasa muda. Jurnal Media Medika.2018; 7: 309-21.

22. Cremen IA,Carson RG. Have standard tests of cognitive function been misappropriated in the study of cognitive enhancement?. Sci Med. 2017; 11: 1-9.

23. Rochman SN. Pengaruh latihan senam otak (brain gym) terhadap peningkatan kemampuan anak tuna grahita ringan. Jurnal Berkala Kedokteran.2015; 5661.

24. Bhinnety M. Struktur dan proses memori. Jurnal Psikologi Universitas Gadjah Mada.2009; 16: 74-88.

25. Christiani O.Efek seduhan teh hijau (green tea) terhadap memori jangka pendek pada wanita dewasa. Jurnal Fak Kedokteran Maranatha. 2017; 41-45.

26. Fajar A.Pengaruh aktivitas fisik maksimal terhadap jumlah leukosit dan hitung jenis leukosit pada atlet softball.[Skripsi].Sumatera:Universita s Negeri Medan.2017; 1-7.

27. Prijo S.Pengaruh senam aerobik intensitas sedang dan intensitas tinggi terhadap persentase lemak badan dan lean body weight. [Skripsi]. Yoyakarta: Universitas Negeri Yogyakarta.2010; 20-6.

28. Made Wisnu. Pemberian senam aerobik intensitas ringan lebih menurunkan persentase lemak subkutan dibandingkan intensitas sedang pada mahasiswi Fisioterapi Fakultas Kedokteran Udayana. [Skripsi]. Denpasar: Universitas Udayana.2012; 4-7.

29. Sari YM.Pengaruh senam aerobik intensitas ringan dan sedang terhadap penurunan persentase lemak badan di aerobic and fitness centre "Fortuna". Jurnal CDK. 2009; 12-6.

30. Palar CM. Manfaat latihan olahraga aerobik terhadap kebugaran fisik manusia. [Skripsi] . Manado: Universitas Sam Ratulangi; 2015; 3: 316-21.

31. Drollette ES, Scudder MR, Raine LB, Moore RD, Saliba BJ, Pontifex MB, et al. Acute exercise facilitates brain function and cognition in children who need it most: an erp study of individual differences in inhibitory control capacity. Neurosci 2014;7: 53-64.

32. Luana L, Paula B,Renata W. A systematic review of cross-cultural adaptation and validation of borg's rating of perceived exertion scale. Phsyeduc. 2017; 1-13.

33. Michael H.Pengaruh aroma terapi sandalwood terhadap memori jangka pendek. Jurnal Media Medika. 2014; 7(1): 7-30.

34. Kirova A, Bays RB,Lagalwar S. Working memory and executive function decline across normal aging, mild cognitive impairment, and alzheimer's disease. Sci Med. 2015; 1 12.

35. Blanton E.The effect of acute exercise on cognitive function in young adult. Sport Sci. 2010; 1: 1-20.

36. Erma Y. Peran kebugaran terhadap prestasi belajar siswa MTS Muhammadiyah $04 \quad$ Blagung 
Kabupaten Boyolali. [Skripsi]. Surakarta: Universitas Sebelas Maret;2012;10-5.

37. Annisa R. Peran serotonin dalam pembelajaran dan memori.Prosiding Seminar Nasional PKM Kesehatan Unisba;2015; 221-24.

38. Muzamil, MS, Martini RD. Hubungan antara tingkat aktivitas fisik dengan fungsi kognitif pada usila di Kelurahan Jati Kecamatan Padang Timur. Jurnal Kesehatan Andalas. 2014; 3: 202-05.

39. Sopiyudin D. Besar sampel dan cara pengambilan sampel dalam Langkahlangkah membuat proposal penelitian bidang kedokteran dan kesehatan. Jakarta: Sagung Seto; 2013.

40. Asuman S, Ermana A,Meneka S. The effect of physical fatigue on shortterm memory. Sci Med.2015: 174; 2425-29.

41. Huldani.Pengaruh latihan aerobik ringan dan sedang terhadap kadar interleukin 8 dan jumlah netrofil. Jurnal Berkala Kedokteran. 2016:12 (1); 61-7. 